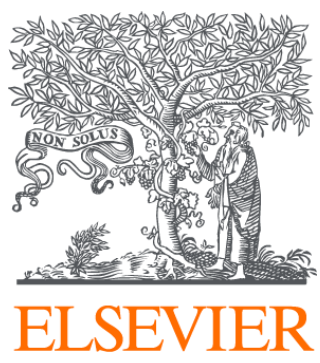

Since January 2020 Elsevier has created a COVID-19 resource centre with free information in English and Mandarin on the novel coronavirus COVID-

19. The COVID-19 resource centre is hosted on Elsevier Connect, the company's public news and information website.

Elsevier hereby grants permission to make all its COVID-19-related research that is available on the COVID-19 resource centre - including this research content - immediately available in PubMed Central and other publicly funded repositories, such as the WHO COVID database with rights for unrestricted research re-use and analyses in any form or by any means with acknowledgement of the original source. These permissions are granted for free by Elsevier for as long as the COVID-19 resource centre remains active. 
Letter to the Editor

\section{Eating disorders in the age of COVID-19}

\section{A R T I C L E I N F O}

\section{Keywords:}

Anorexia nervosa

Bulimia nervosa

Coronavirus

COVID-19

Eating disorder

Suicide

\section{Dear Editor,}

We read with great interest the article "The Psychiatric Impact of the Novel Coronavirus Outbreak" by Carvalho et al. which importantly discusses the broad psychological effects of SARS-CoV-2 (COVID-19) including loneliness, worsening anxiety, distress and insomnia (Carvalho et al., 2020). Other studies have also reported depression and post-traumatic stress due to factors including risk of infection, social isolation, discrimination, and exhaustion (Torales et al., 2020). To date, very limited research has explored the impacts of COVID-19 pandemic on eating disorders (EDs).

Psychosocial stressors stemming from COVID-19 pandemic and resultant stay-at-home orders, may exacerbate ED-related triggers and present a challenging environment for individuals with anorexia nervosa (AN), bulimia nervosa (BN) and binge eating disorder (Hensley, 2020; McMenemy, 2020). For example, limited stock in grocery stores can compromise access to 'safe' routine foods, and food shortages may induce feelings of guilt during food purchases in AN patients recommended to adhere to high-calorie diets (Hensley, 2020). British Broadcasting Corporation News interviewed a woman previously hospitalized for AN, who stated: "I'm scared of how busy [grocery stores] are; the utter panic, the amount of people, the fact my safe foods aren't available, thinking I need to leave food for other people who actually need and deserve to eat and feeling like I don't, as I'm selfish" (McMenemy, 2020). In contrast, leisure time in combination with easy-to-access food within the home can trigger temptations to binge (McMenemy, 2020). Moreover, decreased social supports including limited access to health care professionals (HCPs), and social media content comprising diet and at-home-exercise advice to avoid the 'quarantine 15 ', can contribute to increased distress and ED-related behaviors (Hensley, 2020).

Furthermore, following the 2003 SARS outbreak, eating restrictions were found to trigger the development of psychological disorders in $26.2 \%(n=49)$ of respondents of the General Health Questionnaire (GHQ) (Mihashi et al., 2009). As studies have reported a significant correlation between the GHQ and the Eating Disorders Symptom Impact Scale (EDSIS) (Sepulveda et al., 2008), the current COVID-19 climate may also potentially contribute to the risk of developing EDs in otherwise healthy individuals.
Appropriately managing EDs is crucial to mitigate the potential long-term impacts on individuals with these disorders. For example, individuals with EDs have greater suicidal risk under normal conditions (Smith et al., 2018), and additional COVID-19 pandemic-related stressors could further increase that risk. Thus, in order to minimize the impacts of COVID-19 pandemic on EDs, we encourage HCPs to continue to provide mental health resources to ED patients up to 6 months postisolation (Torales et al., 2020), including virtual group therapy sessions and live meal support through the National Eating Disorders Association (NEDA). Further, we recommend that HCPs encourage ED patients to plan meals and purchase 'safe' food items with a long shelf-life in bulk, when available in store.

Overall, further research is needed to solidify evidence-based approaches for the management of EDs during the current COVID-19-induced crisis.

\section{Author contributions}

All the authors have contributed to and approved the final manuscript.

\section{Declaration of Competing Interest}

Ms. Monica Shah, Ms. Muskaan Sachdeva and Dr. Hariclia Johnston have no relevant financial nor nonfinancial relationships to disclose.

\section{Acknowledgments}

None.

\section{Funding sources}

None.

\section{Supplementary materials}

Supplementary material associated with this article can be found, in the online version, at doi:10.1016/j.psychres.2020.113122. 


\section{References}

Carvalho, P.M.M., Moreira, M.M., de Oliveira, M.N.A., Landim, J.M.M., Neto, M.L.R., 2020. The psychiatric impact of the novel coronavirus outbreak. Psychiatry Res. http://doi.org/10.1016/j.psychres.2020.112902.

Hensley, L., 2020. Why the coronavirus pandemic is triggering those with eating disorders. Global News. https://globalnews.ca/news/6735525/eating-disordercoronavirus/ (accessed 25 May 2020).

McMenemy, R, 2020. Coronavirus and eating disorders: 'I feel selfish buying food'. BBC News. https://www bbc.com/news/uk-england-51962964/(accessed 25 May 2020).

Mihashi, M., Otsubo, Y., Yinjuan, X., Nagatomi, K., Hoshiko, M., Ishitake, T., 2009. Predictive factors of psychological disorder development during recovery following SARS outbreak. Health Psychol. 28 (1), 91-100. https://doi.org/10.1037/a0013674.

Sepulveda, A.R., Whitney, J., Hankins, M., Treasure, J., 2008. Development and validation of an eating disorders symptom impact scale (EDSIS) for carers of people with eating disorders. Health Qual. Life Outcomes 6, 28. https://doi.org/10.1186/1477-
7525-6-28.

Smith, A.R., Zuromski, K.L., Dodd, D.R., 2018. Eating disorders and suicidality: what we know, what we don't know, and suggestions for future research. Curr. Opin. Psychol. 22, 63-67. https://doi.org/10.1016/j.copsyc.2017.08.023.

Torales, J., O'Higgins, M., Castaldelli-Maia, J.M., Ventriglio, A., 2020. The outbreak of COVID-19 coronavirus and its impact on global mental health. Int. J. Soc. Psychiatry. https://doi.org/10.1177/0020764020915212.

Monica Shah ${ }^{\mathrm{a}, *}$, Muskaan Sachdeva ${ }^{\mathrm{a}}$, Hariclia Johnston ${ }^{\mathrm{b}, \mathrm{c}}$ ${ }^{\text {a }}$ Faculty of Medicine, University of Toronto, 1 King's College Cir, Toronto, Ontario M5S 1A8, Canada.

${ }^{\mathrm{b}}$ Family Health Team, Etobicoke Medical Center, Toronto, Ontario, Canada ${ }^{\mathrm{c}}$ Department of Medicine, University of Toronto, Toronto, Ontario, Canada E-mail address: monica.shah@mail.utoronto.ca (M. Shah).

* Corresponding author. 